Pacific Journal of Mathematics

EQUICONTINUITY OF SOLUTIONS OF A QUASI-LINEAR 


\title{
EQUICONTINUITY OF SOLUTIONS OF A QUASI-LINEAR EQUATION
}

\author{
S. E. BoHN
}

On a bounded domain $\Omega$ of the $x y$-plane the equicontinuity of a family of solutions of a linear elliptic partial differential equation is usually demonstrated by showing that the first partial derivatives of solutions are uniformly bounded on compact interior subsets of $\Omega$. Finn [2] uses this same method in showing the equicontinuity for a class of quasi-linear elliptic equations referred to by him as "equations of minimal surface type." However, Finn cites an example which demonstrates that in general bounded collections of solutions of elliptic equations do not have uniformly bounded first partial derivatives on compact interior subsets.

Here we shall consider the question of the equicontinuity of a family of solutions of the quasi-linear equation

$$
L[z] \equiv A(x, y, p, q) r+2 B(x, y, p, q) s+C(x, y, p, q) t=0
$$

where, as usual, $p=z_{x}, q=z_{y}, r=z_{x x}, s=z_{x y}$, and $t=z_{y y}$ and where $A, B$ and $C$ satisfy a growth condition.

Suppose $D$ to be a domain in the $x y$-plane for which

(i) $A>0, A C-B^{2}=1$, and $A, B$, and $C$ are continuous and have continuous first partial derivatives with respect to $p$ and $q$ on $T$ defined by $T \equiv\{(x, y, p, q):(x, y) \in D$ and $-\infty<p, q<+\infty\}$, and

(ii) $(A+C)^{2} \leqq(1 / 125) \log \log \left(p^{2}+q^{2}+e\right)+h(x, y)$ for all $(x, y, p, q) \in T$ where $h(x, y)$ is positive and continuous on $D$.

Henceforth, we shall assume that conditions (i) and (ii) are satisfied whenever reference is made to the equation (1).

THEOREM 1. Let $\Omega$ be a bounded sub-domain of $D$ with boundary $\omega$ such that $\bar{\Omega}=\Omega+\omega \subset D$. If $\left\{f_{\nu}(x, y): \nu \in \mathscr{A}\right\}$ is any collection of functions which are continuous and uniformly bounded on $\omega$ and if corresponding to each $f_{\nu}$ there exists a function $z\left(x, y ; f_{\nu}\right)$ which is of class $C^{2}$ on $\Omega$, is continuous on $\bar{\Omega}$, is a solution of (1) on $\Omega$, and is such that $z\left(x, y ; f_{\nu}\right)=f_{\nu}(x, y)$ on $\omega$, then the collection $\left\{z\left(x, y ; f_{\nu}\right): \nu \in \mathscr{A}\right\}$ is equicontinuous on $\Omega$.

In proving Theorem 1 we shall employ a modification of the method used by Serrin [5] and in so doing depend heavily on the following

Received December 20, 1961. This result is contained in the author's doctoral dissertation presented to the University of Nebraska. Sincerest appreciation is expressed to Professor Lloyd K. Jackson for his direction. 
principle:

Maximum Principle [3]. Let $D$ be any plane domain and consider the function $F(x, y, z, p, q, r, s, t)$ with the following assumptions:

(i) $F$ is continuous in all 8 variables in the region $T$ defined by $T \equiv\{(x, y, z, p, q, r, s, t):(x, y) \in D$ and $-\infty<z, p, q, r, s, t<+\infty\}$ and

(ii) $F_{z}, F_{p}, F_{q}, F_{r}, F_{s}$, and $F_{t}$ are continuous on $T, F_{s}^{2}-4 F_{r} F_{t}<0$, $F_{r}>0$, and $F_{z} \leqq 0$ on $T$.

Let $z_{1}(x, y)$ and $z_{2}(x, y)$ be continuous in a bounded and closed subdomain $\mathscr{X} \subset D$ and of class $C^{2}$ in the interior of $\mathscr{X}$. Furthermore, suppose $z_{1}(x, y) \leqq z_{2}(x, y)$ on the boundary of $\mathscr{X}$ and suppose that in the interior of $\mathscr{X}$

$$
F\left(x, y, z_{1}, z_{1 x}, z_{1 y}, z_{1 x x}, z_{1 x y}, z_{1 y y}\right) \geqq 0
$$

and

$$
F\left(x, y, z_{2}, z_{2 x}, z_{2 y}, z_{2 x x}, z_{2 x y}, z_{2 y y}\right) \leqq 0 .
$$

Then, either $z_{1}(x, y)<z_{2}(x, y)$ in the interior of $\mathscr{X}$ or

$$
z_{1}(x, y) \equiv z_{2}(x, y) \quad \text { on } \mathscr{X} \text {. }
$$

Suppose $M>1$ to be a uniform bound of $\left|f_{\nu}\right|, \nu \in \mathscr{A}$ on $\omega$. Since constants are solutions of (1) it follows from the Maximum Principle that $\left|z_{\nu}(x, y)\right| \equiv\left|z\left(x, y ; f_{\nu}\right)\right|<M$ for $(x, y) \in \bar{\Omega}$ and all $\nu \in \mathscr{A}$. Also, suppose $\left\{z_{\nu}(x, y): \nu \in \mathscr{B}\right\} \equiv\left\{z_{\nu}(x, y): \nu \in \mathscr{A}\right.$ and $z_{\nu}(x, y)>0$ on $\left.\bar{\Omega}\right\}$.

Lemma 1. Let $P_{0}\left(x_{0}, y_{0}\right)$ be any point of $\Omega$ and suppose $\left\{K_{n}\right\}_{n=0}^{n=\infty}$ is a sequence of closed circular disks each having $P_{0}\left(x_{0}, y_{0}\right)$ as its center and $R_{n}=(1 / 7)^{n} R_{0}$ as its radius where $R_{0} \leqq 1$ and $K_{0} \subset \Omega$. Then whenever $z_{2}(x, y)$ is a positive solution of (1) there exists a constant $H$, $0<H<1$, depending only on $R_{0}, \delta \equiv \max h(x, y)$ where $(x, y) \in \bar{\Omega}$, and $M$ such that for all $\nu \in \mathscr{B}$

$$
z_{\nu}(x, y)>H\left[\delta, M, R_{0}\right] z_{\nu}\left(x_{0}, y_{0}\right) \quad \text { on } 0 \leqq\left|P-P_{0}\right| \leqq(1 / 7) R_{0}
$$

and

$$
z_{\nu}(x, y)>H\left[\delta, M,(1 / 7)^{n} R_{0}\right] z_{\nu}\left(x_{0}, y_{0}\right) \geqq H\left[\delta, M,(1 / 7) R_{0}\right](1 / n) z_{2}\left(x_{0}, y_{0}\right)
$$

on $0 \leqq\left|P-P_{0}\right| \leqq(1 / 7)^{n+1} R_{0}, n=1,2,3, \cdots$.

Proof. Let $E$ denote the component of the set

$$
\left\{(x, y) \in K_{0}: z_{\nu}(x, y)>(1 / 2) z_{\nu}\left(x_{0}, y_{0}\right)\right\}
$$

${ }^{1}$ See Bers and Nirenberg [1] for a proof of a Harnack inequality for solutions of the uniformly elliptic equation (1). 
which contains $P_{0}\left(x_{0}, y_{0}\right)$. We can apply the Maximum Principle to conclude that $E$ must contain an arc of the circumference of $K_{0}$. Hence, there is a Jordan arc $\Gamma$ contained in $E$ with one end at $\left(x_{0}, y_{0}\right)$ and the other end at a point $\left(x_{1}, y_{1}\right)$ on the circumference of $K_{0}$ which is such that with the exception of $\left(x_{1}, y_{1}\right) \Gamma$ is contained in the interior of $E$. Let $K^{2}$ and $K^{3}$ be the two closed disks each of which has radius $\sqrt{5} / 2 R_{0}$ and each of which has the points $\left(x_{0}, y_{0}\right)$ and $\left(x_{1}, y_{1}\right)$ on its circumference. Each point $(x, y) \in K^{2} \cap K^{3}$ satisfies at least one of the following conditions:

(a) $(x, y) \in \Gamma \cup b d r y\left(K^{2} \cap K^{3}\right)$,

(b) $(x, y)$ is in a subdomain of $K^{2}$ the boundary of which consists of $\operatorname{arcs}$ of $\Gamma$ and arcs of the circumference of $K^{2}$,

(c) $(x, y)$ is in a subdomain of $K^{3}$ the boundary of which consists of arcs of $\Gamma$ and arcs of the circumference of $K^{3}$.

Let $K^{4}$ be the closed disk with center at

$$
\left(x_{4}, y_{4}\right) \equiv\left(\frac{3 x_{0}+x_{1}}{4}, \frac{3 y_{0}+y_{1}}{4}\right)
$$

and radius (3/4) $R_{0}$ and let $\left(x_{2}, y_{2}\right)$ and $\left(x_{3}, y_{3}\right)$ be the respective centers of $K^{2}$ and $K^{3}$. It is clear that

$$
\begin{aligned}
& \left\{(x, y):\left(x-x_{2}\right)^{2}+\left(y-y_{2}\right)^{2} \leqq \varepsilon^{2}\left(\sqrt{5} / 2 R_{0}\right)^{2}\right\} \subset \operatorname{comp} K_{0}, \\
& \left\{(x, y):\left(x-x_{3}\right)^{2}+\left(y-y_{3}\right)^{2} \leqq \varepsilon^{2}\left(\sqrt{5} / 2 R_{0}\right)^{2}\right\} \subset \operatorname{comp} K_{0},
\end{aligned}
$$

and

$$
\left\{(x, y):\left(x-x_{4}\right)^{2}+\left(y-y_{4}\right)^{2} \leqq \varepsilon^{2}\left(3 / 4 R_{0}\right)^{2}\right\} \subset \text { interior }\left(K^{2} \cap K^{3}\right)
$$

where $\varepsilon=1 / 10$.

Consider the function

$$
v(x, y ; \xi, \eta ; r) \equiv \frac{N\left(e^{-\alpha \sigma^{2}}-e^{-\alpha r^{2}}\right)}{1-e^{-\alpha r^{2}}}
$$

defined on the region

$$
S(\xi, \eta ; r) \equiv\left\{(x, y): \varepsilon^{2} r^{2} \leqq \sigma^{2}=(x-\xi)^{2}+(y-\eta)^{2} \leqq r^{2}\right\} \cap K_{0}
$$

where $\alpha>0$ and $N=1 / 2 z_{\nu}\left(x_{0}, y_{0}\right)$. In this region

$$
v_{x}^{2}+v_{y}^{2}=\frac{4 \alpha^{2} N^{2} \sigma^{2} e^{-2 \alpha \sigma^{2}}}{\left(1-e^{-\alpha r^{2}}\right)^{2}} \leqq \frac{4 N^{2}}{\sigma^{2}} \leqq \frac{M^{2}}{\varepsilon^{2} r^{2}} \quad \text { for all } \nu \in \mathscr{B} .
$$

Furthermore, $v<N$ on $S(\xi, \eta ; r), v=0$ where $\sigma=r$, and $v>0$ where $\sigma<r$. If $A, B$, and $C$ are evaluated at $\left(x, y, \gamma v_{x}, \gamma v_{y}\right)$, the following succession of inequalities are valid in $S(\xi, \eta ; r)$ where $\gamma, 0<\gamma<1$, is any fixed real number. 


$$
\begin{aligned}
& L[\gamma v]\left(1-e^{-\alpha r^{2}}\right)=2 \alpha \gamma N e^{-\alpha \sigma^{2}}\left\{2 \alpha \left[A(x-\xi)^{2}+2 B(x-\xi)(y-\eta)\right.\right. \\
& \left.\left.+C(y-\eta)^{2}\right]-(A+C)\right\} \\
& \geqq 2 \alpha \gamma N e^{-\alpha \sigma^{2}}\left\{\frac{4 \alpha\left(A C-B^{2}\right) \sigma^{2}}{(A+C)+\sqrt{(A+C)^{2}-4\left(A C-B^{2}\right)}}-(A+C)\right\} \\
& \geqq \frac{2 \alpha \gamma N e^{-\alpha \sigma^{2}}}{(A+C)}\left\{2 \alpha \varepsilon^{2} r^{2}-(A+C)^{2}\right\} \\
& \geqq \frac{2 \alpha \gamma N e^{-\alpha \sigma^{2}}}{(A+C)}\left\{2 \alpha \varepsilon^{2} r^{2}-\frac{1}{125} \log \log \left[\gamma^{2}\left(v_{x}^{2}+v_{y}^{2}\right)+e\right]-h(x, y)\right\} \\
& \geqq \frac{2 \alpha \gamma N e^{-\alpha \sigma^{2}}}{(A+C)}\left\{2 \alpha \varepsilon^{2} r^{2}-\frac{1}{125} \log \log \left[\frac{M^{2}}{\varepsilon^{2} r^{2}}+e\right]-\delta\right\}
\end{aligned}
$$

where $\delta \equiv \max h(x, y)$ for $(x, y) \in \bar{\Omega}$. Now $L[\gamma v]_{1}^{\prime} \geqq 0$ on $S(\xi, \eta ; r)$ if one chooses

$$
\alpha \geqq \frac{1}{250 \varepsilon^{2} r^{2}}\left\{\log \log \left[\frac{M^{2}}{\varepsilon^{2} r^{2}}+e\right]+125 \delta\right\} .
$$

Let

$$
v_{2}(x, y) \equiv v\left(x, y ; x_{2}, y_{2} ; \sqrt{5 / 2} R_{0}\right)
$$

and

$$
v_{3}(x, y) \equiv v\left(x, y ; x_{3}, y_{3}, \sqrt{5} / 2 R_{0}\right)
$$

Let

$$
\left.\alpha=\frac{32}{45 R_{0}^{2}} \log \log \left[\left(4 M / 3 \varepsilon R_{0}\right)^{2}+e\right]+125 \delta\right\}
$$

and assume that $(x, y)$ is in the interior of $K^{2} \cap K^{3}$ and either $(x, y) \in \Gamma$ or $(x, y)$ satisfies condition (b), then we can apply the Maximum Principle to conclude that $z_{2}(x, y)>v_{2}(x, y)$. Similarly, if $(x, y)$ is in the interior of $K^{2} \cap K^{3}$ and either $(x, y) \in \Gamma$ or $(x, y)$ satisfies (c), we can conclude that $z_{\nu}(x, y)>v_{3}(x, y)$. Thus, for all $(x, y) \in$ interior $\left(K^{2} \cap K^{3}\right)$ it follows that

$$
z_{\nu}(x, y)>\min \left[v_{2}(x, y), v_{3}(x, y)\right] .
$$

Now on the circle $\left(x-x_{4}\right)^{2}+\left(y-y_{4}\right)^{2}=\varepsilon^{2}\left(3 / 4 R_{0}\right)^{2}$

$$
\begin{aligned}
& \gamma_{0} \equiv \min \left[v_{2}(x, y), v_{3}(x, y)\right]=N \frac{\exp \left(-\frac{5}{4} \lambda^{2} \alpha R_{0}^{2}\right)-\exp \left(-\frac{5}{4} \alpha R_{0}^{2}\right)}{1-\exp \left(-\frac{5}{4} \alpha R_{0}^{2}\right)} \\
&>N\left(1-\lambda^{2}\right) \exp \left(-\frac{5}{4} \lambda^{2} \alpha R_{0}^{2}\right)
\end{aligned}
$$


where $\lambda=[(\sqrt{17}+3 \varepsilon) \sqrt{5}] / 10<1$. Another application of the Maximum Principle yields $z_{2}(x, y)>\left(\gamma_{0} / N\right) v_{4}(x, y)$ on $S\left(x_{4}, y_{4}, 3 / 4 R_{0}\right)$ where

$$
v_{4}(x, y) \equiv v\left(x, y ; x_{4}, y_{4} ; 3 / 4 R_{0}\right) \text {. }
$$

Now the annulus $S\left(x_{4}, y_{4} ; 3 / 4 R_{0}\right)$ contains the disk with center at $\left(x_{0}, y_{0}\right)$ and radius $1 / 7 R_{0}$. On this disk

$$
\begin{aligned}
v_{4}(x, y) \geqq \gamma_{1} & \equiv N \frac{\exp \left(-\frac{9}{16} \rho^{2} \alpha R_{0}^{2}\right)-\exp \left(-\frac{9}{16} \alpha R_{0}^{2}\right)}{1-\exp \left(-\frac{9}{16} \alpha R_{0}^{2}\right)} \\
& >N\left(1-\rho^{2}\right) \exp \left(-\frac{9}{16} \rho^{2} \alpha R_{0}^{2}\right)
\end{aligned}
$$

where $\rho=11 / 21$.

Therefore, on the disk with center $\left(x_{0}, y_{0}\right)$ and radius $1 / 7 R_{0}$.

$$
\begin{aligned}
z_{\nu}(x, y)>\frac{\gamma_{0} \gamma_{1}}{N}> & \frac{1}{2}\left(1-\lambda^{2}\right)\left(1-\rho^{2}\right) \exp \left[-\left(\frac{5}{4} \lambda^{2}+\frac{9}{16} \rho^{2}\right) \alpha R_{0}^{2}\right] z_{\nu}\left(x_{0}, y_{0}\right) \\
> & \frac{1}{2}\left(1-\lambda^{2}\right)\left(1-\rho^{2}\right) \exp \left(-\frac{45}{32} \alpha R_{0}^{2}\right) z_{\nu}\left(x_{0}, y_{0}\right) \\
> & \frac{1}{2}\left(1-\lambda^{2}\right)\left(1-\rho^{2}\right) \exp (-125 \delta) \\
& \cdot \exp \left\{-\log \log \left[\left(4 M / 3 \varepsilon R_{0}\right)^{2}+e\right]\right\} z_{\nu}\left(x_{0}, y_{0}\right) \\
> & H\left[\delta, M, R_{0}\right] z_{\nu}\left(x_{0}, y_{0}\right) \\
& \quad \text { on } 0 \leqq\left|P-P_{0}\right| \leqq(1 / 7) R_{0} \text { for all } \nu \in \mathscr{B}
\end{aligned}
$$

where

$$
H\left[\delta, M, R_{0}\right]=\frac{1}{2}\left(1-\lambda^{2}\right)\left(1-\rho^{2}\right) \exp (-125 \delta)\left\{\log \left[\left(\frac{4 M}{3 \varepsilon R_{0}}\right)^{2}+e\right]\right\}^{-1} .
$$

Now by an inductive argument one concludes that

$$
\begin{aligned}
& H\left[\delta, M,(1 / 7)^{n} R_{0}\right]=\frac{1}{2}\left(1-\lambda^{2}\right)\left(1-\rho^{2}\right) \exp (-125 \delta) \\
& \cdot\left\{\log \left[\left(\frac{4 M(7)^{n}}{3 \varepsilon R_{0}}\right)^{2}+e\right]\right\}^{-1} \geqq \frac{1}{n} H\left[\delta, M, 1 / 7 R_{0}\right]
\end{aligned}
$$

and

$$
z_{\nu}(x, y)>\frac{1}{n} H\left[\delta, M, 1 / 7 R_{0}\right] z_{\nu}\left(x_{0}, y_{0}\right) \quad \text { on } 0 \leqq\left|P-P_{0}\right| \leqq(1 / 7)^{n+1} R_{0},
$$

$n=1,2,3, \cdots$ for all $\nu \in \mathscr{B}$, thus proving the lemma.

LEMMA 2. Using the assumptions of Lemma 1 


$$
z_{2}(x, y)<\frac{1}{H\left[\delta, M, 7 / 8 R_{0}\right]} z_{2}\left(x_{0}, y_{0}\right)
$$

for $0 \leqq\left|P-P_{0}\right| \leqq 1 / 8 R_{0}$ for all $\nu \in \mathscr{B}$.

Proof. Follows directly from Lemma 1.

It is of interest to note that if $z(x, y)$ is a positive solution of $A(x, y, p, q) r+2 B(x, y, p, q) s+C(x, y, p, q) t=0$ in a domain $T$, then for any compact $U \subset T$ and compact $S$ properly contained in $U$ there is an $H>0$ depending only on the bound of $z(x, y)$ on $U$ and the distance from $S$ to the boundary of $U$ such that

$$
\frac{1}{H} z\left(x_{2}, y_{2}\right) \leqq z\left(x_{1}, y_{1}\right) \leqq H z\left(x_{2}, y_{2}\right)
$$

for any two points $\left(x_{1}, y_{1}\right)$ and $\left(x_{2}, y_{2}\right)$ in $S$.

LEMma 3. If $z_{\nu}(x, y) \nu \in \mathscr{B}$ is a solution of (1) on the interior of a closed circular disk $K_{0}$ of radius $R_{0} \leqq 1$ with center $P_{0}\left(x_{0}, y_{0}\right)$, then there exists a continuous decreasing function $g_{P_{0}}(r), 0 \leqq r<R_{0}, g_{P_{0}}(0)=$ 1 , and a continuous increasing function $f_{P_{0}}(r), 0 \leqq r<R_{0}, f_{P_{0}}(0)=1$ such that

$$
g_{P_{0}}(r) z_{\nu}\left(x_{0}, y_{0}\right) \leqq z_{\nu}(x, y) \leqq f_{P_{0}}(r) z_{\nu}\left(x_{0},{ }^{r} y_{0}\right)
$$

for $0 \leqq\left|P-P_{0}\right| \leqq r$ where $g$ and $f$ are independent of $\nu$.

Proof. Define

$$
g_{P_{0}}(r) \equiv \inf _{\nu \in \mathscr{O}} \inf _{\left|P-P_{0}\right| \leqq r} \frac{z_{\nu}(x, y)}{z_{\nu}\left(x_{0}, y_{0}\right)}
$$

and

$$
f_{P}(r) \equiv \sup _{\nu \in \mathscr{P} P} \sup _{\left|P-P_{0}\right| \leqq r} \frac{z_{\nu}(x, y)}{z_{\nu}\left(x_{0}, y_{0}\right)}
$$

By Lemma 1, Lemma 2, and an argument similar to that used in Kellogg [4] (page 263) $f_{P_{0}}(r)$ and $g_{P_{0}}(r)$ exist for each $0 \leqq r<R_{0}$. Using standard arguments it is clear that

$$
\lim _{r \rightarrow r_{0}^{-}} \inf _{\nu \in \mathscr{S}} \inf _{\left|P-P_{0}\right| \leqq r} \frac{z_{\nu}(x, y)}{z_{\nu}\left(x_{0}, y_{0}\right)}=\inf _{\nu \in \mathscr{B}} \inf _{\left|P-P_{0}\right| \leqq r_{0}} \frac{z_{\nu}(x, y)}{z_{\nu}\left(x_{0}, y_{0}\right)}
$$

for $0<r_{0}<R_{0}$ and

$$
\lim _{r-r_{0}^{-}} \sup _{\nu \in \mathscr{S}} \sup _{\left|P-P_{0}\right| \leqq r} \frac{z_{\nu}(x, y)}{z_{\nu}\left(x_{0}, y_{0}\right)}=\sup _{\nu \in \mathscr{P}} \sup _{\left|P-P_{0}\right| \leqq r_{0}} \frac{z_{\nu}(x, y)}{z_{\nu}\left(x_{0}, y_{0}\right)}
$$


for $0<r_{0}<R_{0}$. Also,

$$
\lim _{r \rightarrow 0^{+}} \inf _{\nu \in \mathscr{D}^{\infty}} \inf _{\left|P-P_{0}\right| \leqq r} \frac{z_{\nu}(x, y)}{z_{\nu}\left(x_{0}, y_{0}\right)}=1 \text {. }
$$

This follows by observing that whenever $z_{\nu}(x, y)>0$ for $0 \leqq\left|P-P_{0}\right| \leqq R_{0}$

$$
z_{\nu}(x, y)>H\left[\delta, M, R_{0}\right] z_{\nu}\left(x_{0}, y_{0}\right) \text { for } 0 \leqq\left|P-P_{0}\right| \leqq 1 / 7 R_{0}
$$

and all $\nu \in \mathscr{B}$. This latter inequality implies

$$
\begin{aligned}
z_{\nu}(x, y) & -H\left[\delta, M, R_{0}\right] z_{\nu}\left(x_{0}, y_{0}\right) \\
& >H\left[\delta, M, 1 / 7 R_{0}\right]\left\{z_{\nu}\left(x_{0}, y_{0}\right)-H\left[\delta, M, R_{0}\right] z_{\nu}\left(x_{0}, y_{0}\right)\right\}
\end{aligned}
$$

for $0 \leqq\left|P-P_{0}\right| \leqq(1 / 7)^{2} R_{0}$ and all $\nu \in \mathscr{B}$. Thus, for $0 \leqq\left|P-P_{0}\right|<$ $(1 / 7)^{2} R_{0}$ and all $\nu \in \mathscr{B}$

$$
z_{\nu}(x, y)>\left[1-\left(1-H\left[\delta, M, R_{0}\right]\right)\left(1-H\left[\delta, M, 1 / 7 R_{0}\right]\right)\right] z_{\nu}\left(x_{0}, y_{0}\right)
$$

By induction

$$
\begin{aligned}
z_{\nu}(x, y) & >\left[1-\prod_{i=0}^{n}\left(1-H\left[\delta, M,(1 / 7)^{i} R_{0}\right]\right)\right] z_{\nu}\left(x_{0}, y_{0}\right) \\
& >\left[1-\left(1-H\left[\delta, M, R_{0}\right]\right) \prod_{i=1}^{n}\left(1-H\left[\delta, M, 1 / 7 R_{0}\right] \frac{1}{i}\right)\right] z_{\nu}\left(x_{0}, y_{0}\right)
\end{aligned}
$$

for $0 \leqq\left|P-P_{0}\right| \leqq(1 / 7)^{n+1} R_{0}$ and all $\nu \in \mathscr{B}$. Hence,

$$
\begin{aligned}
1-\inf _{\nu \in \Im^{\beta}\left|P-P_{0}\right| \leqq(1 / 7) n+1} & \frac{z_{\nu}(x, y)}{z_{\nu}\left(x_{0}, y_{0}\right)} \\
& <\exp \left(-H\left[\delta, M, R_{0}\right]-H\left[\delta, M, 1 / 7 R_{0}\right] \sum_{i=1}^{n} \frac{1}{i}\right) .
\end{aligned}
$$

(4) then follows by the usual argument.

Suppose $P$ is any point in the circle $0 \leqq\left|P-P_{0}\right| \leqq(1 / 7)^{n} R_{0} /\left[1+(1 / 7)^{n}\right]$ and let $K$ be the interior of a closed circular disk of radius $1 /\left[1+(1 / 7)^{n}\right] R_{0}$ about $P$. Since $z_{\nu}(x, y)>0$ on $0 \leqq\left|P-P_{0}\right| \leqq R_{0}$ we have $z_{\nu}\left(x^{\prime}, y^{\prime}\right)>0$ on $0 \leqq\left|P-P^{\prime}\right| \leqq R_{0} /\left[1+(1 / 7)^{n}\right]$ for all $\nu \in \mathscr{B}$. Also

$$
\begin{aligned}
z_{\nu}\left(x^{\prime}, y^{\prime}\right)-[1 & -\left(1-H\left[\delta, M, 7 / 8 R_{0}\right]\right)^{\prime} \\
& \left.\cdot \prod_{i=1}^{n}\left(1-H\left[\delta, M, 1 / 8 R_{0}\right] \frac{1}{i}\right)\right] z_{\nu}(x, y)>0
\end{aligned}
$$

on

$$
0 \leqq\left|P-P^{\prime}\right| \leqq(1 / 7)^{n+1} \frac{1}{1+(1 / 7)^{n}} R_{0} \quad \text { for all } \nu \in \mathscr{B} .
$$

Now $P_{0}\left(x_{0}, y_{0}\right)$ is such a point $P^{\prime}\left(x^{\prime}, y^{\prime}\right)$; therefore, for all $\nu \in \mathscr{B}$ and $0 \leqq\left|P-P_{0}\right| \leqq(1 / 7)^{n+1}\left[1 /\left(1+(1 / 7)^{n}\right)\right] R_{0}$ 


$$
\begin{aligned}
z_{\nu}\left(x_{0}, y_{0}\right)>[1- & \left(1-H\left[\delta, M, 7 / 8 R_{0}\right]\right) \\
\left.\cdot \prod_{i=1}^{n}\left(1-H\left[\delta, M, 1 / 8 R_{0}\right] \frac{1}{i}\right)\right] z_{\nu}(x, y), & \sup _{\nu \in \mathscr{P}\left|P-P_{0}\right| \leqq(1 / 7)^{n+1}\left[1 /\left(1+(1 / 7)^{n}\right)\right] R_{0}} \frac{z_{\nu}(x, y)}{z_{\nu}\left(x_{0}, y_{0}\right)}-1 \\
& <\exp \left(-H\left[\delta, M, 7 / 8 R_{0}\right]-H\left[\delta, M, 1 / 8 R_{0}\right] \sum_{i=1}^{n} \frac{1}{i}\right)
\end{aligned}
$$

and we may conclude that

$$
\lim _{r \rightarrow 0^{+}} \sup _{\nu \in \mathscr{S}^{\infty}} \sup _{\left|P-P_{0}\right| \leqq r} \frac{z_{\nu}(x, y)}{z_{\nu}\left(x_{0}, y_{0}\right)}=1
$$

We will now show that

$$
\lim _{r \rightarrow r_{0}^{+}} \sup _{\nu \in \mathscr{S}} \sup _{\left|P-P_{0}\right| \leqq r} \frac{z_{\nu}(x, y)}{z_{\nu}\left(x_{0}, y_{0}\right)}=\sup _{\nu \in \mathscr{P}} \sup _{\left|P-P_{0}\right| \leqq r_{0}} \frac{z_{\nu}(x, y)}{z_{\nu}\left(x_{0}, y_{0}\right)}
$$

for $0 \leqq r_{0}<R_{0}$.

Suppose the contrary, then since $f_{P_{0}}(r)$ is increasing $\lim _{r \rightarrow r_{0}^{+}} f_{P_{0}}(r)>$ $f_{P_{0}}(r)$. Hence, there exists an $\varepsilon>0$ and a decreasing sequence $\left\{r_{n}\right\}$ converging to $r_{0}$ such that for all positive integers $n f_{P_{0}}\left(r_{n}\right)-f_{P_{0}}\left(r_{0}\right)>\varepsilon$. By the definition of supremum there exists for the above $\varepsilon$ and each $n$ a function $z_{n}(x, y)$ such that

$$
\sup _{\nu \in \mathscr{P}} \sup _{\left|P-P_{0}\right| \leqq r_{n}} \frac{z_{\nu}(x, y)}{z_{\nu}\left(x_{0}, y_{0}\right)}-\sup _{\left|P-P_{0}\right| \leqq r_{n}} \frac{z_{n}(x, y)}{z_{n}\left(x_{0}, y_{0}\right)} \leqq \frac{\varepsilon}{2}
$$

and thus,

$$
\sup _{\left|P-P_{0}\right| \leqq r_{n}} \frac{z_{n}(x, y)}{z_{n}\left(x_{0}, y_{0}\right)}-\sup _{\nu \in \mathscr{F}} \sup _{\left|P-P_{0}\right| \leqq r_{0}} \frac{z_{\nu}(x, y)}{z_{\nu}\left(x_{0}, y_{0}\right)}>\frac{\varepsilon}{2}
$$

By the Maximum Principle

$$
\sup _{\left|P-P_{0}\right| \leqq r_{n}} \frac{z_{n}(x, y)}{z_{n}\left(x_{0}, y_{0}\right)}
$$

is assumed at some point $P_{n}\left(x_{n}, y_{n}\right)$ on $\left|P-P_{0}\right|=r_{n}$. Hence, there exists a sequence of points $\left\{P_{n}\left(x_{n}, y_{n}\right)\right\}$ which contains a convergent subsequence which converges to a point $P_{0}^{\prime}\left(x_{0}^{\prime}, y_{0}^{\prime}\right) \in\left|P-P_{0}\right|=r_{0}$. Suppose our sequence is such without relabeling. Let

$$
\varepsilon_{1}=\varepsilon / \sup _{\nu \in \mathscr{S}} \sup _{\left|P-P_{0}\right| \leqq r_{0}} \frac{z_{\nu}(x, y)}{z_{\nu}\left(x_{0}, y_{0}\right)} \text {. }
$$

Therefore, 


$$
\begin{aligned}
\frac{z_{n}\left(x_{n}, y_{n}\right)}{z_{n}\left(x_{0}, y_{0}\right)}-\frac{z_{n}\left(x_{0}^{\prime}, y_{0}^{\prime}\right)}{z_{n}\left(x_{0}, y_{0}\right)} & \geqq \frac{z_{n}\left(x_{n}, y_{n}\right)}{z_{n}\left(x_{0}, y_{0}\right)}-\sup _{\nu \in \mathscr{P}\left|P-P_{0}\right| \leqq r_{0}} \sup _{z_{\nu}\left(x_{0}, y_{0}\right)} \\
& >\frac{\varepsilon_{1}}{2} \sup _{\nu \in \mathscr{P}} \sup _{\left|P-P_{0}\right| \leqq r_{0}} \frac{z_{\nu}(x, y)}{z_{\nu}\left(x_{0}, y_{0}\right)} .
\end{aligned}
$$

Let us center our attention on the point $P_{0}^{\prime}\left(x_{0}^{\prime}, y_{0}^{\prime}\right)$. Then, using (6), there exists a $\delta_{1}>0$ such that

$$
\sup _{\nu \in \mathscr{B}} \sup _{\left|P-P_{0}^{\prime}\right| \leqq r} \frac{z_{\nu}(x, y)}{z_{\nu}\left(x_{0}^{\prime}, y_{0}^{\prime}\right)}-1 \leqq \frac{\varepsilon_{1}}{2} \quad \text { if } r<\delta_{1} .
$$

Also, by (4) there exists a $\delta_{2}>0$ such that if $r<\delta_{2}$

$$
1-\inf _{\nu \in \mathscr{O}} \inf _{\left|P-P_{0}^{\prime}\right| \leqq r} \frac{z_{\nu}(x, y)}{z_{\nu}\left(x_{0}^{\prime}, y_{0}^{\prime}\right)} \leqq \frac{\varepsilon_{1}}{2} \text {. }
$$

Thus, if $\left|P-P_{0}^{\prime}\right| \leqq \min \left[\delta_{1}, \delta_{2}\right]$

$$
\left|\frac{z_{\nu}(x, y)}{z_{\nu}\left(x_{0}^{\prime}, y_{0}^{\prime}\right)}-1\right| \leqq \frac{\varepsilon_{1}}{2}
$$

It then follows that if $\left|P_{n}-P_{0}^{\prime}\right| \leqq \min \left[\delta_{1}, \delta_{2}\right]$

$$
\begin{aligned}
\frac{\varepsilon_{1}}{2} \sup _{\nu \in \mathscr{P}} \sup _{\left|P-P_{0}\right| \leq r_{0}} \frac{z_{\nu}(x, y)}{z_{\nu}\left(x_{0}, y_{0}\right)} & <\frac{z_{n}\left(x_{n}, y_{n}\right)-z_{n}\left(x_{0}^{\prime}, y_{0}^{\prime}\right)}{z_{n}\left(x_{0}, y_{0}\right)} \\
& <\frac{z_{n}\left(x_{n}, y_{n}\right)-z_{n}\left(x_{0}^{\prime}, y_{0}^{\prime}\right)}{z_{n}\left(x_{0}^{\prime}, x_{0}^{\prime}\right)} \cdot \frac{z_{n}\left(x_{0}^{\prime}, y_{0}^{\prime}\right)}{z_{n}\left(x_{0}, y_{0}\right)} \\
& <\frac{z_{n}\left(x_{n}, y_{n}\right)-z_{n}\left(x_{0}^{\prime}, y_{0}^{\prime}\right)}{z_{n}\left(x_{0}^{\prime}, y_{0}^{\prime}\right)} \cdot \sup _{\nu \in \mathscr{P}^{*}} \sup _{\left|P-P_{0}\right| \leq r_{0}} \frac{z_{\nu}(x, y)}{z_{\nu}\left(x_{0}, y_{0}\right)} \\
& <\frac{\varepsilon_{1}}{2} \sup _{\nu \in \mathscr{P}\left|P-P_{0}\right| \leq r_{0}} \frac{z_{\nu}(x, y)}{z_{\nu}\left(x_{0}, y_{0}\right)},
\end{aligned}
$$

a contradiction. By a similar argument we may conclude

$$
\operatorname{Lim}_{r \rightarrow r_{0}^{+}} \inf _{\nu \in \mathscr{D}} \inf _{\left|P-P_{0}\right| \leqq r} \frac{z_{\nu}(x, y)}{z_{\nu}\left(x_{0}, y_{0}\right)}=\inf _{\nu \in \mathscr{O}} \inf _{\left|P-P_{0}\right| \leqq r_{0}} \frac{z_{\nu}(x, y)}{z_{\nu}\left(y_{0}, x_{0}\right)},
$$

Hence, by (2), (3), (7), and (8) our lemma is true.

Proof of Theorem 1. Recall that for $\nu \in \mathscr{A}\left|f_{\nu}\right|<M$ on $\omega$ and $\left|z_{\nu}(x, y)\right|<M$ on $\bar{\Omega}$. Also, for all $\nu \in \mathscr{A}, z_{\nu}(x, y)+M$ satisfies (1) and $z_{\nu}(x, y)+M>0$ on $\bar{\Omega}$.

Let $P_{0}\left(x_{0}, y_{0}\right)$ be any point of $\Omega$ and assume $K$ is a closed circular disk whose center is $P_{0}\left(x_{0}, y_{0}\right)$ and such that $K \subset \Omega$. Hence, by Lemma 3 there exists positive continuous functions $f_{P_{0}}(r)$ and $g_{P_{0}}(r)$ (independent of $\nu$ ) such that $\lim _{r \rightarrow 0} f_{P_{0}}(r)=1, \lim _{r \rightarrow 0} g_{P_{0}}(r)=1$, and on the interior of $K$

$$
g_{P_{0}}(r)\left[z_{\nu}\left(x_{0}, y_{0}\right)+M\right] \leqq z_{\nu}(x, y)+M \leqq f_{P_{0}}(r)\left[z_{\nu}\left(x_{0}, y_{0}\right)+M\right]
$$


and

$$
\begin{aligned}
-\left|z_{\nu}\left(x_{0}, y_{0}\right)+M\right|\left|g_{P_{0}}(r)-1\right| & \leqq z_{\nu}(x, y)-z_{\nu}\left(x_{0}, y_{0}\right) \\
& \leqq\left|z_{\nu}\left(x_{0}, y_{0}\right)+M\right|\left|f_{P_{0}}(r)-1\right|
\end{aligned}
$$

for all $\nu \in \mathscr{A}$. It then follows that since $\left\{z_{\nu}(x, y): \nu \in \mathscr{A}\right\}$ is uniformly bounded on $\bar{\Omega}$ that $\left\{z_{\nu}(x, y): \nu \in \mathscr{A}\right\}$ is equicontinuous on $\Omega$ thus proving Theorem 1.

\section{REFERENCES}

1. Bers and Nirenberg, On linear and nonlinear elliptic boundary value problems in the plane, Convegno Internazionale sulle Equazioni Derivate Parziali, (1954), 141-167.

2. Finn, On Equations of minimal surface type, Annals of Math., 60 (1954), 397-416.

3. Hopf, Elementarie Betrachtungen uber die Losungen partieller Differentialgleichungen zweiter Ordnung vom elliptischen Typus, Sitzungsberichte Preuss. Akad. Wiss., 19 (1927), $147-152$.

4. Kellogg, Foundation of Potential Theory, Dover Publications, Inc., 1953.

5. Serrin, On the Harnack inequality for linear elliptic equations, Journ. D Analyse Math, 4 (1954-55), 292-308.

Bowling Green State University 


\section{PACIFIC JOURNAL OF MATHEMATICS}

\section{EDITORS}

\author{
Ralph S. Phillips \\ Stanford University \\ Stanford, California \\ M. G. Arsove \\ University of Washington \\ Seattle 5 , Washington
}

\author{
A. L. Whiteman \\ University of Southern California \\ Los Angeles 7, California \\ Lowell J. Paige \\ University of California \\ Los Angeles 24, California
}
E. F. BECKENBACH
D. DERRY
ASSOCIATE EDITORS
T. M. CHERRY
M. OHTSUKA
H. L. ROYDEN
E. G. STRAUS
E. SPANIER
F. WOLF

\section{SUPPORTING INSTITUTIONS}

\author{
UNIVERSITY OF BRITISH COLUMBIA \\ CALIFORNIA INSTITUTE OF TECHNOLOGY \\ UNIVERSITY OF CALIFORNIA \\ MONTANA STATE UNIVERSITY \\ UNIVERSITY OF NEVADA \\ NEW MEXICO STATE UNIVERSITY \\ OREGON STATE UNIVERSITY \\ UNIVERSITY OF OREGON \\ OSAKA UNIVERSITY \\ UNIVERSITY OF SOUTHERN CALIFORNIA
}

\author{
STANFORD UNIVERSITY \\ UNIVERSITY OF TOKYO \\ UNIVERSITY OF UTAH \\ WASHINGTON STATE UNIVERSITY \\ UNIVERSITY OF WASHINGTON \\ AMERICAN MATHEMATICAL SOCIETY \\ CALIFORNIA RESEARCH CORPORATION \\ SPACE TECHNOLOGY LABORATORIES \\ NAVAL ORDNANCE TEST STATION
}

Mathematical papers intended for publication in the Pacific Journal of Mathematıcs should be typewritten (double spaced), and the author should keep a complete copy. Manuscripts may be sent to any one of the four editors. All other communications to the editors should be addressed to the managing editor, L. J. Paige at the University of California, Los Angeles 24, California.

50 reprints per author of each article are furnished free of charge; additional copies may be obtained at cost in multiples of 50 .

The Pacific Journal of Mathematics is published quarterly, in March, June, September, and December. Effective with Volume 13 the price per volume (4 numbers) is $\$ 18.00$; single issues, $\$ 5.00$. Special price for current issues to individual faculty members of supporting institutions and to individual members of the American Mathematical Society: $\$ 8.00$ per volume; single issues $\$ 2.50$. Back numbers are available.

Subscriptions, orders for back numbers, and changes of address should be sent to Pacific Journal of Mathematics, 103 Highland Boulevard, Berkeley 8, California.

Printed at Kokusai Bunken Insatsusha (International Academic Printing Co., Ltd.), No. 6, 2-chome, Fujimi-cho, Chiyoda-ku, Tokyo, Japan.

PUBLISHED BY PACIFIC JOURNAL OF MATHEMATICS, A NON-PROFIT CORPORATION

The Supporting Institutions listed above contribute to the cost of publication of this Journal, but they are not owners or publishers and have no responsibility for its content or policies. 


\section{Pacific Journal of Mathematics}

\section{Vol. 12 , No. 4 \\ April, 1962}

Tsuyoshi Andô, On fundamental properties of a Banach space with a cone ..... . 1163

Sterling K. Berberian, A note on hyponormal operators ................ 1171

Errett Albert Bishop, Analytic functions with values in a Frechet space . . . . . . . 1177

(Sherman) Elwood Bohn, Equicontinuity of solutions of a quasi-linear equation ............................................ 1193

Andrew Michael Bruckner and E. Ostrow, Some function classes related to the class of convex functions . . . . . . . . . . . . . . . . . . . . . . . . 1203

J. H. Curtiss, Limits and bounds for divided differences on a Jordan curve in the complex domain . . ................................. 1217

P. H. Doyle, III and John Gilbert Hocking, Dimensional invertibility . . . . . . . . 1235

David G. Feingold and Richard Steven Varga, Block diagonally dominant matrices and generalizations of the Gerschgorin circle theorem ................. 1241

Leonard Dubois Fountain and Lloyd Kenneth Jackson, A generalized solution of the boundary value problem for $y^{\prime \prime}=f\left(x, y, y^{\prime}\right) \ldots \ldots \ldots \ldots \ldots \ldots \ldots \ldots \ldots$

Robert William Gilmer, Jr., Rings in which semi-primary ideals are primary. . . . . 1273

Ruth Goodman, K-polar polynomials .......................... 1277

Israel Halperin and Maria Wonenburger, On the additivity of lattice completeness ........................................... 1289

Robert Winship Heath, Arc-wise connectedness in semi-metric spaces . . . . . . . . 1301

Isidore Heller and Alan Jerome Hoffman, On unimodular matrices . . . . . . . . . . . 1321

Robert G. Heyneman, Duality in general ergodic theory . . . . . . . . . . . . . . . 1329

Charles Ray Hobby, Abelian subgroups of p-groups . . . . . . . . . . . . . . . 1343

Kenneth Myron Hoffman and Hugo Rossi, The minimum boundary for an analytic

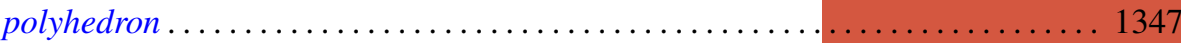

Adam Koranyi, The Bergman kernel function for tubes over convex cones ........ 1355

Pesi Rustom Masani and Jack Max Robertson, The time-domain analysis of a continuous parameter weakly stationary stochastic proces.

William Schumacher Massey, Non-existence of almost-complex structures on

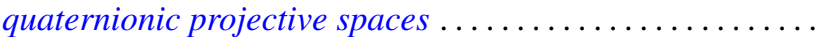

Deane Montgomery and Chung-Tao Yang, A theorem on the action of $\mathrm{SO}(3) \ldots . .1385$

Ronald John Nunke, A note on Abelian group extensions . . . . . . . . . . . . . 1401

Carl Mark Pearcy, A complete set of unitary invariants for operators generating finite $W^{*}$-algebras of type $I$

Edward C. Posner, Integral closure of rings of solutions of linear differential equations.

Duane Sather, Asymptotics. III. Stationary phase for two parameters with an application to Bessel functions.

J. Śladkowska, Bounds of analytic functions of two complex variables in domains

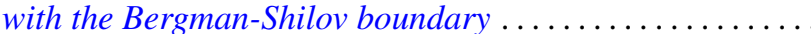

Joseph Gail Stampfli, Hyponormal operators .

George Gustave Weill, Some extremal properties of linear combinations of kernels

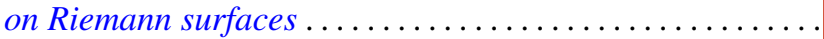

